\title{
IDENTIFIKASI SENYAWA METABOLIT SEKUNDER PADA EKSTRAK DAUN GAYAM (Inocarpus Fagifer Fosb) DENGAN MENGGUNAKAN KLT
}

\section{Identification of Secondary Metabolite Compounds on The Extract of Gayam Leaves (Inocarpus Fagifer Fosb) Using TLC}

\section{Rohama ${ }^{1 *}$ \\ Zainuddin $^{2}$ \\ *I,2 Sari Mulia University, Banjarmasin City, South Borneo 70238, Indonesia \\ *email: apt.rohama@gmail.com}

\begin{abstract}
Abstrak
Pohon Gayam tersebar luas diwilayah Indonesia, Tumbuhan gayam (Inocarfus Fegifer Fosb) juga digunakan sebagai obat BAB berdarah pada masyarakat dengan cara merebus batang dan diminum air rebusan nya. Gayam selain berkhasiat sebagai obat juga digunakan sebagai makanan dimasyarakat di daerah Banjarmasin. Masyarakat awam tentunya banyak belum mengetahui manfaat gayam serta kandungan nilai gizinya.

Penelitian mengenai identifikasi senyawa metabolit sekunder pada ekstrak daun Gayam (Inocarpus Fagifer Fosb) dengan menggunakan KLT dimana Daun Gayam (Inocarpus Fagifer Fosb) di ekstraksi dengan metode maserasi, ekstrak kental yang diperoleh kemudian dilakukan uji identifikasi senyawa metabolit sekunder dengan uji pereaksi warna dan KLT. Hasil identifikasi senyawa metabolit daun gayam (Inocarfus Fegifer Fosb) dengan uji pereaksi warna dan KLT menunjukan hasil uji positif adanya senyawa alkaloid, flavonoid, terpenoid, saponin.
\end{abstract}

\section{Kata Kunci:}

Stroke

Kekuatan

Genggaman tangan

Keywords:

Stroke

Strength

Hand grip

\begin{abstract}
The Gayam tree is widespread in the territory of Indonesia, the Gayam plant (Inocarfus Fegifer Fosb) is also used as a medicine for bloody bowel movements in the community by boiling the stems and drinking boiled water. Besides having medicinal properties, Gayam is also used as food in the community in the Banjarmasin area. The common people certainly do not know the benefits of gayam and its nutritional value.

Research on the identification of secondary metabolite compounds in Gayam leaf extract (Inocarpus Fagifer Fosb) using TLC where Gayam Leaves (Inocarpus Fagifer Fosb) was extracted by maceration method, the thick extract obtained was then carried out by testing the identification of secondary metabolites with color reagent and TLC. The results of the identification of the compound metabolite of gayam leaves (Inocarfus Fegifer Fosb) by color reagent and TLC test showed positive test results for alkaloids, flavonoids, terpenoids, saponins.
\end{abstract}

(C) year The Authors. Published by Institute for Research and Community Services Universitas Muhammadiyah Palangkaraya. This is Open Access article under the CC-BY-SA License (http://creativecommons.org/licenses/by-sa/4.0/). DOI: https://doi.org// 0.33084/jsm.vxix.xxx.

\section{PENDAHULUAN}

Senyawa metabolit sekunder adalah sumber bahan kimia yang tidak pernah habis, sebagai sumber inovasi dalam penemuan dan pengembangan obat-obat baru ataupun untuk menunjang berbagai kepentingan industri. Selain itu, sebagai identifikasi awal dalam membuat sediaan farmasi dari senyawa kimia bahan alam yang memiliki nilai tambah produk (Noval, Melviani, Novia, Syahrina, 2020).

Senyawa metabolit sekunder yang terdapat dalam tumbuhan merupakan zat bioaktif yang berkaitan dengan kandungan kimia dalam tumbuhan, sehingga sebagian tumbuhan dapat digunakan sebagai bahan obat (Kurniawati et al., 2020). Tanpa adanya suatu senyawa bioaktif dalam tumbuhan secara umum tumbuhan tersebut tidak dapat digunakan sebagai obat (Adikara, 2013).

Pada saat ini pohon buah Gayam tersebar luas diwilayah Indonesia yang meliputi pulau Jawa, Kalimantan, Sumatera, dan sebagian Semenanjung Malaya. Seiring dengan berkembangnya pembibitan beragam tanaman buah-buahan dengan berbagai pola pembiakan menjadikan. tanaman gayam semakin terpinggirkan. Pohon gayam pelan namun pasti tersaingi oleh jenis yang kebanyakan masyarakat 
menganggap punya nilai ekonomi yang lebih bagus. Eksplorasi senyawa kimia dari bahan alam sangat memiliki dampak yang signifikan terhadap masyarakat dalam pengembangan produk farmasi yang memiliki khasiat farmakologi dan dapat dimanfaatkan secara luas (Noval, et al., 2020).

Gayam selain berkhasiat sebagai obat juga digunakan sebagai makanan dimasyarakat di daerah Banjarmasin. Beberapa hal tersebut antara lain menjadi penyebab masyarakat kurang berminat untuk mengolah dan memanfaatkan buah gayam. Masyarakat awam tentunya banyak belum mengetahui manfaat biji gayam serta kandungan nilai gizinya. Tumbuhan gayam (Inocarfus Fegifer Fosb) juga digunakan sebagai obat BAB berdarah pada masyarakat dengan cara merebus batang dan diminum air rebusan nya.

Ekstrak etanol kulit batang gayam mengandung senyawa flavonoid serta mempunyai aktivitas sebagai antioksidan (Anastasia, 2015), ekstrak etanol daun gayam memiliki nilai aktivitas antioksidan $\mathrm{IC}_{50}$ berturutturut sebesar 508I.2 ug/ml Lestari 2018), ekstrak kulit batang gayam menggandung flavonoid dan fenol (santi, 20I5), berdasarkan manfaat gayam yang telah diketahui, maka tanaman ini dapat digunakan sebagai bahan dilakukannya penelitian yaitu identifikasi senyawa metabolit sekunder daun gayam dengan menggunakan $K L T$, dengan adanya penelitian ini diharapkan dapat menambah data pemanfaatan tanaman sekaligus wujud pelestarian tanaman. Kromatografi lapis tipis adalah salah satu metode identifikasi komponen menggunakan fase diam. berupa plat dengan lapisan bahan adsorben inert, KLT merupakan alat satu jenis kromatografi analitik. KLT sering digunakan untuk identifikasi awal, karena banyak keuntungan menggunakan KLT, diantaranya adalah sederhana dan murah.

\section{METODOLOGI}

\section{Alat dan Bahan}

Alat yang digunakan yaitu gunting seperangkat alat maserasi, waterbath, rotary evaporator, cawan penguap, corong kaca, batang pengaduk, alat alat gelas, plat KLT, tangas air kertas saring, pipa kapiler, gunting dan pisau. tabung, reaksi, dan lampu ultraviolet.

Bahan yang digunakan adalah ekstrak daun gayam (Inocarpus Fagifer Fosb), aquadest, etanol 70\%, serbuk magnesium, $\mathrm{HCl} 5 \mathrm{M}, \mathrm{FeCl}_{3}$ I\%, n- heksan, kloroform.

\section{Metode Penelitian}

Persiapan Alat dan Bahan

Sampel daun gayam (Inocarpus Fagifer Fosb) didapat dari daerah kota Banjarmasin, Kalimantan Selatan.

Pembuatan Ekstrak Etanol Daun Gayam

Tahapan ekstraksi adalah sebagai berikut:

I. Simplisia daun gayam (Inocarpus Fagifer Fosb), dimasukkan ke dalam bejana maserasi.

2. Dimasukkan etanol ke dalam bejana sampai merendam simplisia setinggi $2-3 \mathrm{~cm}$

3. Bejana maserasi ditutup dan biarkan rendaman selama 3 hari sambil sesekali di aduk

4. Cairan hasil ekstraksi dikeluarkan dari bejana dengan disaring

5. Filtrat kemudian diuapkan menggunakan rotary evaporator sampai didapatkan ekstrak kental (Noval et al., 2019).

Identifikasi Senyawa Metabolit Sekunder Ekstrak Daun Gayam dengan Pereaksi Warna

I. Flavonoid Cara yang pertama uji shinoda: Ekstrak daun gayam (Inocarfus fegifer Fosb) yang dilarutkan dalam $2 \mathrm{~mL}$ etanol ditambahkan dan serbuk magnesium dan 5-10 tetes HCL. Mengamati serbuk perubahan warna yang terjadi (Warna merah jingga sampai merah menunjukan adanya flavanon, flavonol, flavanolol, dan dihidroflavonol) (Harborne, 1987).

2. Terpenoid dengan pereaksi LibermannBuchard: Ekstrak daun gayam (Inocarfus fegifer Fosb) yang dilarutkan dalam $2 \mathrm{~mL}$ etanol ditambahkan 3-5 tetes pereaksi liberman- 
Burchard hinga terbentuknya warna hijau hingga biru (Harborne, 1987).

3. Alkaloid dengan pereaksi dragendorf: ekstrak dilarutkan dalam $2 \mathrm{~mL}$ etanol masukan ke dalam tabung reaksi menambahkan pereaksi dragendorf. (warna oranye mendekati merah yang terbentuk menunjukan adanya senyawa alkaloid) (Tiwari,et al., 2017).

4. Saponin: Ekstrak daun gayam (Inocarfus fegifer) yang dilarutkan dalam $2 \mathrm{~mL}$ etanol yang diperiksa ke dalam tabung tabung reaksi. Menambahkan $10 \mathrm{ml}$ air panas, kemudian dinginkan. Kocok kuat kuat 10 selama 10 detik. Amati hasil pengujian (Terdapat saponin dengan ciri terbentuknya buih yang bertahan selama 10 menit, setinggi I sampai $10 \mathrm{~cm}$ ) selanjunya menambahkan I tetes $\mathrm{HCL} 2 \mathrm{~N}$, buih tidak hilang maka mengandung saponin (Tiwari,et al., 2017).

5. Identifikasi tanin: Ekstrak daun gayam (Inocafus fegifer Fosb) yang dilarutkan dalam $2 \mathrm{~mL}$ etanol dan tambahkan 5-10 tetes larutan $\mathrm{FeCl} 33 \%$ terbentuknya warna hijau biru hingga kehitaman (Noval et al., 2019).

Identifikasi Senyawa Metabolit Sekunder Ekstrak Daun Gayam dengan KLT

Siapkan plat KLT Ekstrak daun gayam (Inocarfus fegifer fosb) yang akan digunakan, Larutan bahan uji dan atau pembanding yang sudah disiapkan ditotol kan pada lempeng (jarak antara totolan sekitar I-I,5 cm) dengan volume tertentu, jarak I,5-2 cm dari tepi bawah lempeng, diameter totolan diusahakan sekecil mungkin dan dibiarkan mengering dan beri tanda pada jarak rambat yang dikehendaki. Memasukan lempeng kedalam bejana yang sudah dijenuhkan dengan fase gerak, dengan posisi tegak dan bagian tepi bawah tercelup dalam fase gerak, tetapi totolan tidak sampai terendam. Menutup rapat bejana, fase gerak dibiarkan merambat hingga batas jarak rambat,
Mengeluarkan lempeng dan mengeringkan diudara dan Perhatikan bercak yang timbul dengan sinar tampak ultraviolet pada panjang gelombang $254 \mathrm{~nm}$ dan $366 \mathrm{~nm}$ selanjutnya diukur dan dicatat jarak rambat setiap bercak yang timbul dan fase gerak dari titik penotolan sehingga diperoleh nilai Rf.

Pereaksi semprot Uji alkaloid dengan menyemprot pada plat KLT dengan pereaksi dragendorf yang akan menunjukan noda coklat jingga berlatar kuning (Harborne, 1996). Uji triterpenoid dengan menyemprot pada plat KLT dengan pereaksi liebermann-buchard ( anhidrida asetat: asam sulfat pekat 3:I) yang akan menunjukan warna hijau/biru pada steroid dan merah/ungu triterpenoid (Harborne, 1996).

\section{HASIL DAN PEMBAHASAN}

Tumbuhan gayam (Inocarfus Fegifer Fosb) juga digunakan sebagai obat $B A B$ berdarah pada masyarakat dengan cara merebus batang dan diminum air rebusan nya. Gayam selain berkhasiat sebagai obat juga digunakan sebagai makanan dimasyarakat di daerah Banjarmasin. Masyarakat awam tentunya banyak belum mengetahui manfaat gayam serta kandungan nilai gizinya.

Identifikasi senyawa metabolit sekunder ekstrak daun Gayam (Inocarfus Fegifer Fosb) dilakukan dengan menggunakan pereaksi warna dan KLT. Adapun hasil identifikasi senyawa metabolit sekunder daun gayam dapat dilihat pada tabel berikut:

Tabel I. Hasil Identifikasi Senyawa Metabolit Sekunder Ekstrak Daun Gayam (Inocarfus Fegifer Fosb) dengan Pereaksi Warna

\begin{tabular}{cccc}
\hline No & $\begin{array}{c}\text { Metabolit } \\
\text { Sekunder }\end{array}$ & Pereaksi & Hasil \\
\hline I & Alkaloid & Dragendorf & $\begin{array}{c}(+) \text { Warna orange } \\
\text { mendekati merah }\end{array}$ \\
\hline 2 & Flavonoid & Shinoda & $(+)$ Warna merah jingga \\
\hline 3 & Terpenoid & $\begin{array}{c}\text { Liebermann } \\
\text { Buchard }\end{array}$ & $\begin{array}{c}(+) \text { Warna hijau hingga } \\
\text { biru }\end{array}$ \\
\hline 4 & Saponin & Buih & $(+)$ Buih 2 cm \\
\hline 5 & Tanin & FeCl3 & $(-)$ Warna hijau coklat \\
\hline
\end{tabular}


Tabel II. Hasil Identifikasi Senyawa Metabolit Sekunder Ekstrak Daun Gayam (Inocarfus Fegifer Fosb) dengan

KLT

\begin{tabular}{ccc}
\hline No & $\begin{array}{l}\text { Metabolit } \\
\text { Sekunder }\end{array}$ & Hasil (UV 366 dan UV 254) \\
\hline I & Alkaloid & $(+)$ \\
\hline 2 & Flavonoid & $(+)$ \\
\hline 3 & Terpenoid & $(+)$ \\
\hline 4 & Saponin & $(+)$ \\
\hline 5 & Tanin & $(-)$
\end{tabular}

Berdasarkan pengujian yang dilakukan, didapatkan data sebagaimana dalam tabel I dan II.

Hasil dari pengujian senyawa fitokimia menyatakan bahwa ekstrak daun gayam mengandung senyawa alkaloid, flavonoid, terpenoid dan saponin. Senyawa flavonoid yang teridentifikasi disebabkan karena senyawa flavonoid termasuk dalam senyawa fenol yang apabila direaksikan dengan basa akan terbentuk warna akibat terjadinya sistem konjugasi dari gugus aromatik, senyawa flavonoid selain memiliki kemampuan sebagai antioksidan juga dapat berfungsi sebagai antimikroba, anti alergi, sitotoksisitas dan anti inflamasi (Kusnadi, 2017).

Terbentuknya busa pada identifikasi saponin disebabkan adanya glikosida yang mampu membentuk busa didalam air yang terhidrolisis menjadi glukosa dan senyawa lainnya, saponin memiliki banyak manfaat seperti antibakteri, antifungi, menurunkan kolesterol dalam darah dan menghambat pertumbuhan sel tumor (Nugrahani, 2016).

Dari hasil penelitian menunjukan hasil uji positif adanya terpenoid dalam sampel. Senyawa terpenoid yang teridentifikasi disebabkan karena terbentuknya senyawa komplek dengan pereksi libermann-buchard.

Senyawa alkaloid yang teridentifikasi disebabkan karena senyawa alkaloid mengandung atom nitrogen yang mempunyai pasangan electron bebas sehingga dapat digunakan untuk membentuk ikatan kovalen koordinat dengan ion logam. Nitrogen pada alkaloid akan bereaksi dengan ion logam k+ dari kalium tetraiodomerkurat (II) membentuk kompleks kaliumalkaloid yang mengendap (marliana, 2005).

Pengujian menggunakan KLT akan diamati pada lampu UV 254 dan 366, pengamatan pada lampu UV 254 yang terjadi adalah lempeng KLT akan berfluorosensi dan sampel yang tampak akan menunjukkan warna yang gelap. Penampakkan noda yang terjadi pada lampu UV 254 dan 366 terjadi karena adanya interaksi antara sinar UV dengan indikator fluorosensi yang ada pada lempeng. Hasil yang didapatkan adalah ekstrak daun gayam positif mengandung senyawa alkaloid, flavonoid, terpenoid dan saponin.

\section{KESIMPULAN}

Berdasarkan penelitian yang telah dilakukan ekstrak daun gayam (Inocarfus Fegifer Fosb) dengan uji pereaksi warna dan Kromatografi Lapis Tipis warna menunjukan hasil uji positif adanya senyawa alkaloid, flavonoid, terpenoid, dan saponin

\section{UCAPAN TERIMA KASIH}

Peneliti mengucapkan terimakasih kepada keluarga, teman-teman yang telah memberikan dukungan selama pengerjaan penelitian ini.

\section{REFERENSI}

I. Noval, N., Melviani, M., Novia, N. and Syahrina, D. 2020. Formulasi Dan Evaluasi Sediaan Obat Kumur (Mouthwash) Dari Ekstrak Etanol Tanaman Bundung (Actinoscirpus Grossus) Sebagai Antiseptik Mulut. Jurnal Surya Medika (JSM). 6, I (Aug. 2020),

II2-120. DOI:https://doi.org/10.33084/jsm.v6i1.1626.

2. Kurniawati, Darini, Noval Noval, and Kunti Nastiti. 2020. "POTENSI ANTISEPTIK POLIHERBAL DAUN SIRIH (Piper Betle), KULIT JERUK NIPIS (Citrus Aurantifolia) DAN TANAMAN BUNDUNG 
(Actinuscirpus Grossus) PADA TINDAKAN KEPERAWATAN DAN KEBIDANAN." Dinamika Kesehatan: Jurnal Kebidanan Dan Keperawatan II(I): 420-3I.

3. Adikara, I Putu Arya, 2013 Studi Histopatologi Hati Tikus Putih (Rattus novergicus) yang diberi Ekstrak Etanol Daun Kedondong (Spondias dulcis) Secara Oral.(nama kota) Buletin Veteriner Udayana. ISSN: 2085-2495. Vol. 5 No. 2.

4. Noval, N., Nastiti, K., Nugraha, D., Rahmadani, R., \& Alawiyah, T. 2020 Dec 30. PRODUK INOVASI HAND SANITIZER DARI AKAR BAJAKAH SEBAGAI UPAYA PENCEGAHAN DI MASA PANDEMI COVID-19. LOGISTA - Jurnal Ilmiah Pengabdian kepada Masyarakat. [Online] 4:2

5. Anastasia, M. H. 2015. Isolasi, Identifikasi Dan Uji Aktivitas Antioksidan Senyawa Flavonoid Pada Kulit Batang Gayam. Denpasar: Bachelor thesis, Universitas Udayana.

6. Harborne, J.B. 1987. Metode Fitokimia Penuntun Cara Modern Menganalisis Tumbuhan.Bandung. Penerbit ITB.

7. Kusnadi, Devi Egie T. 2017. Isolasi dan identifikasi senyawa flavonoid pada ekstrak daun seledri (Apium gaveolens L.) dengan metode refluks. Pancasakti Science Education Journal. 2(I): 56-57. Tersedia pada: https://www.researchgate.net/publication/318 342858 ISOLASI_DAN IDENTIFIKASI SEN YAWA_FLAVONOID_PADA_EKSTRAK_D AUN_SELEDRI_Apiumgraveolens L_DENGAN_METODE_REFLUK $\underline{S}$ [Diakses 17 Juli 2020]

8. Lestari, Astuti (2018). Isolasi Dan Identifikasi Senyawa Metabolisme Sekunder Dari Fraksi Etil Asetat Batang Benalu (Dendrophthoe Falcata (L.F). Jogyakarta. Skripsi Tidak Diterbitkan. Fakultas Matematika dan IlmuPengetahuan Alam. UNY : Yogyakarta.

9. Marliana, S. D., Suryanti, V dan Suyono. (2005). Skrining Fitokimia dan Analisis Kromatografi Lapis Tipis Komponen Kimia Buah Labu Siam (Sechium edule Jacq. Swartz.) dalam Ekstrak Etanol. Biofarmasi. 3(I)

10. Noval, N., Yuwindry, I. and Syahrina, D. (2019) 'Phytochemical Screening and Antimicrobial Activity of Bundung Plants Extract by Dilution Method', Jurnal Surya Medika. doi: 10.33084/jsm.v5il.954.
II. Nugrahani R, Andayani Y, Hakim A. 2016. Skrining fitokimia dari ekstrak buah buncis (Phaseolus vulgaris L) dalam sediaan serbuk. Jurnal Penelitian Pendidikan IPA. 2(I): 35-42. Tersedia pada: http://jurnalfkip.unram.ac.id/Index.php/PK/arti cle/download/198/194 [Diakses 17 Juli 2020]

12. Sri Rahayu Santi. 2015. aktivitas antioksidan total flavonoid dan fenol kulit batang gayam (Inocarfus Fegifer Fosb). Bali. jurnal kimia 9 (2), : 160-168.

13. Tiwari P, Kumar B, Kaur G, Kaur H. 201 I. Phytochemical Screening and Extraction. A review International Pharmaceutica Sciencia. I(I). Tersedia pada:https://www.semanticscholar.org/paper/ Phytochemical-screening-and-Extraction\%3AA-Review-TiwariKaur/979e9b8ddd64c025 I740bd8ff2f65f3c9a I b3408 [Diakses 3 Maret 2020] 